\title{
Mothers' Health and Work-Related Factors at 11 Weeks Postpartum
}

\author{
Pat McGovern, $\mathrm{PbD}, \mathrm{MPH}$ \\ Bryan Dowd, $P b D^{1}$ \\ Dwenda Gjerdingen, $M D, M S^{2}$ \\ Rada Dagher, MPH \\ Laurie Ukestad, $M S^{1}$ \\ David McCaffrey, BA ${ }^{1}$ \\ Ulf Lundberg, $P b D^{3}$ \\ 'School of Public Health, University of \\ Minnesota, Minneapolis, Minn \\ ${ }^{2}$ Medical School, University of Minnesota, \\ Minneapolis, Minn \\ ${ }^{3}$ Department of Psychology, Stockholm \\ University, Stockholm, Sweden
}

Conflicts of interest: none reported

\section{CORRESPONDING AUTHOR}

Pat McGovern, PhD, MPH

School of Public Health

University of Minnesota

420 Delaware St. SE, Mayo MMC 807

Minneapolis, MN 55455

pmcg@umn.edu

\begin{abstract}
PURPOSE Many new mothers return to work soon after childbirth. This study examines personal and work-related factors associated with the postpartum health of employed women 11 weeks after childbirth.
\end{abstract}

METHODS Using a prospective cohort design, we recruited 817 Minnesota mothers into the study while they were hospitalized for childbirth in 2001. Telephone interviews were conducted at 5 and 11 weeks postpartum. Eligible women were 18 years or older, employed, and spoke English and gave birth to a singleton infant. Multivariate models using instrumental variables (2-stage least squares) were used to estimate personal and employment characteristics associated with women's physical and mental health and postpartum symptoms.

RESULTS At 11 weeks postpartum, 661 participants (81\% of enrollees) completed a full interview, and $50 \%$ of participants had returned to work. On average, women reported 4.1 (SD 3.2) childbirth-related symptoms, most frequently fatigue (43\%). Factors significantly associated with better health outcomes included better preconception health, the absence of prenatal mood problems, more control over work and home activities, more social support at work and home, and less job stress.

CONCLUSIONS The findings suggest postpartum women need to be evaluated regarding their fatigue levels and mental and physical symptoms. Women whose fatigue or postpartum symptoms limit daily role function may find it helpful to have health care clinicians counsel them on strategies to decrease job stress, increase social support at work and home, and certify their use of intermittent family and medical leave to help them manage their symptoms.

Ann Fam Med 2007;5:519-527. DOI: 10.1370/afm.751

\section{INTRODUCTION}

I n 2005 the labor force participation rate by mothers of infants was at $54 \%,{ }^{1}$ contrasting with $38 \%$ in $1980 .{ }^{2}$ Sixty percent of employed, firsttime mothers giving birth in the United States between 1996 and 2000 had returned to work by 3 months after giving birth. ${ }^{3}$ Given the increased prevalence of new mothers in the workplace, it is important to understand the personal and work factors that promote women's postpartum health and successful return to work.

The traditional medical perspective of the postpartum period refers to the time after childbirth that is required for the reproductive organs to return to their nonpregnant state, a process that takes approximately 6 weeks. ${ }^{4}$ Many physicians perceive this time as one requiring little assistance other than the recommended single postpartum visit. Many women, however, experience mild to moderate discomforts for several weeks (eg, from fatigue, breast soreness, cesarean section, or episiotomy) ${ }_{1}^{4,5}$ and some face serious conditions, such as postpartum depression, ${ }^{6}$ that may limit daily function for months. ${ }^{7}$

Women's recovery from childbirth and their resumption of work and family commitments are likely to be influenced by such personal factors 
as preexisting health status, parity, breastfeeding, the availability of social support from family and friends, ${ }^{8-12}$ and work-related factors, eg, the timing of return to work, job stress, and workplace support. ${ }^{13}$ Few studies, however, have examined these factors in association with women's postpartum health.

Breastfeeding has health benefits for infants and their mothers as described elsewhere. ${ }^{8}$ Healthy People 2010 initiatives promote a goal of $75 \%$ breastfeeding initiation through the early postpartum period ${ }^{14}$; however, national estimates from 2002 reveal that $68 \%$ of children were breastfed to any extent at 7 days, declining to $52 \%$ at 3 months. ${ }^{15}$ Ten states have laws promoting breastfeeding in the workplace. ${ }^{16}$ Despite the recent growth of state policies, relatively little is known about the effect of breastfeeding on women's well-being upon return to work after childbirth.

Relatively few longitudinal studies have examined social support and women's postpartum health. Five studies found a positive association, ${ }^{10-13,17}$ whereas 1 study reported no association. ${ }^{14}$ The positive associations are observed across various measures of support, health outcomes, and time of measurement after childbirth. ${ }^{10-13,17}$ Only 2 studies addressed employed women, ${ }^{10,13}$ however, and only 1 examined the impact of work-related support. Killien et al reported that lack of workplace peer cohesion was associated with a reduction in women's daily role function. ${ }^{13}$

Family and medical leave policy is an important employment benefit for many new mothers. Under the federal Family and Medical Leave Act (FMLA) of 1993, eligible parents are entitled to 12 weeks of full-time, job-protected leave from work in association with childbirth or adoption. Even so, only $62 \%$ of US employees work at FMLA-covered establishments and are eligible for leave. ${ }^{18}$ To be FMLA-eligible, employees must have been employed for at least 12 months, plus have worked at least 1,250 hours before the leave begins, and must work at a location with 50 or more employees living within 75 miles of the site of employment. ${ }^{19}$ For women who are ineligible for FMLA benefits, state policy or an individual employer's policy may offer some form of leave benefit. A state-by state guide to leave policies has been published elsewhere. ${ }^{20}$

Longer childbirth-related leaves had a positive association with maternal health in 2 studies conducted in Minnesota before FMLA was enacted. Studies found a positive association of leave on maternal vitality after 12 weeks of leave, ${ }^{5}$ and on maternal mental health at 15 weeks, and at 24 weeks or more. ${ }^{4}$

We extended previous research by examining the association of breastfeeding, social support at home and work, job stress, and the timing of return to work on women's health at 11 weeks after childbirth in a sample of employed women.

\section{METHODS}

\section{Theory}

The theory underlying this analysis is a hybrid model of health and workforce participation adapted from Becker $^{21}$ and Grossman, ${ }^{22}$ as described in an earlier report. ${ }^{8}$ Women's postpartum health was modeled as a function of (1) predetermined variables, which include personal, perinatal, postpartum, and work factors; and (2) endogenous choice variables, which include employment status, health services used, and breastfeeding status.

\section{Study Design and Participants}

This prospective cohort study of employed postpartum women was undertaken at 3 community hospitals from Minneapolis-St. Paul, Minnesota (for details, see McGovern et al). ${ }^{8}$ Participants were recruited from the population of women aged 18 years and older admitted to the hospital for childbirth in 2001. Sample selection criteria included residing in the 7-county area, giving birth to a healthy singleton infant, speaking English, being employed, and planning to return to work after childbirth. Study participants represented $42 \%$ of births at the study hospitals (71\% of those eligible). Details of the sample were reported by McGovern et al. ${ }^{8}$

\section{Data}

A questionnaire was developed using measures with established reliability and validity. All staff were trained in unbiased interviewing. After receiving approval from the institutional review boards, nurses reviewed women's medical charts and interviewed potentially eligible women regarding employment criteria and informed consent. University staff conducted telephone interviews using a 4-week window (eg, 10 to 14 weeks postpartum). On average, women completed the interview at 11 weeks postpartum (mean 11.2 weeks; SD 1.2 weeks). The full interview required 45 minutes, whereas a 10 -minute mini-interview was available for women who quit employment or had time constraints. We compared the 2 groups of women by interview status to assess for bias, although only data from full interviews were included in the multivariate analysis.

\section{Measures of Dependent and Independent Variables}

The dependent variables in this study were (1) the physical component summary (PCS) score $;(2)$ the mental component summary (MCS) score; and ( 3 ) a 
postpartum symptom score. The PCS and MCS were taken from the SF-12 (Version 2), a 12-item general health measure that is summarized into physical and mental component scores. ${ }^{23}$ SF-12 scores above and below 50 are above and below the average in the US population. ${ }^{23}$ The 28 -item postpartum symptom score was adapted from an earlier study. ${ }^{4}$ All of the health outcome measures utilized a 4 -week recall period. The independent variables included personal and work factors as described in an earlier publication. ${ }^{8}$

\section{Statistical Analyses}

Instrumental variables regression in the form of 2-stage least squares (2SLS) was used to address the participants' endogenous choices of some of our independent variables, such as breast-feeding, employment and leave status, and use of health services. Our concern was that there might be unobserved variables that affect these endogenous explanatory variables and the subsequent maternal health outcomes, resulting in confounding (omitted variables bias). ${ }^{24}$ The structural form equations used to estimate maternal health are detailed in the Supplemental Appendix, available online-only at http://www. annfammed.org/cgi/content/full/5/6/519/DC1.

Another issue is whether the coefficient on the explanatory variables in the health equations should be constrained to be the same for women who are still on leave as it is for women back at work. Chow tests ${ }^{24}$ were conducted to test the equality of coefficients for these 2 groups of women. Test results showed that the regression coefficients for each health outcome did not differ significantly when comparing women on leave with women who had returned to work: mental health $\left(F_{22,615}=1.12 ; P=521.31\right)$; physical health $\left(F_{22,615}=1.46\right.$; $P=.08)$; and symptoms $\left(F_{22,615}=0.78 ; P=.75\right)$.

\section{RESULTS}

Among 2,736 women giving birth at the study hospitals during the enrollment period, 1,157 met eligibility criteria (42\% of births). Among 1,579 ineligible women, $581(37 \%)$ were ineligible because of demographic or health factors, and 998 women (63\%) were ineligible on employment-related criteria, either because they were not working in the year before pregnancy or were not planning to work after this childbirth. The study enrolled 817 women $(71 \%$ of eligible women).

Women were interviewed at enrollment (while hospitalized for childbirth), and at 5 and 11 weeks after childbirth. Of the 817 women enrolled, at 11 weeks postpartum, 661 participants ( $81 \%$ of enrollees) completed a full interview, 70 women $(8.6 \%)$ completed a mini-interview, and $86(10.4 \%)$ could not be reached. Women completing the full interview at 11 weeks postpartum (were significantly older, more frequently white, and college-educated relative to other enrollees. Differences in health status and poverty measures between groups were not statistically significant (Table 1).

The comparability of the data in this analysis with national data was reported in an earlier study. ${ }^{8}$ The study population was slightly less likely to be married $(77 \%$ married) than new mothers nationwide (83\% married). ${ }^{25}$ The proportion of white and Native American mothers in the study population was similar to national data $(78 \%$ and $1 \%$, respectively), but the proportion of African American mothers was slightly less than national data ( $9 \%$ vs $15 \%$ ), and the proportion of Asian mothers was slightly higher than nationwide estimates ( $11 \%$ vs $5 \%){ }^{26}$

\section{Descriptive Statistics}

Characteristics of the 661 women completing the full interview at 11 weeks postpartum are displayed in Table 2. On average, participants were 30 years old $86 \%$ were white, $89 \%$ were married or partnered, and $50 \%$ had returned to work. New mothers scored slightly and significantly better (higher) than the national data on physical health (mean 55.7 vs $52.7 ; \mathrm{SD}$ 5.2, 9.1; $z=8.5 ; P<.000$ ) and mental health (mean 50.4 vs $47.2 ;$ SD $7.3,12.1 ; z=6.7 ; P<.000)$ for women aged 25 to 34 years.

Women's childbirth-related symptoms generally declined with time. On average, women reported 4.1 (SD 3.2) childbirth-related symptoms at 11 weeks postpartum, down slightly from 6.2 (SD 3.5) symptoms at 5 weeks postpartum. When symptoms specific to breastfeeding were removed from the symptom summary score, a slight decline in symptoms was again evident. On average, women reported 3.9 symptoms (SD 3.0) at 11 weeks postpartum relative to 4.9 symptoms (SD 3.1) at 5 weeks postpartum.

The frequency of symptoms at both 5 and 11 weeks postpartum is reported in Table 3. Fatigue was the most frequent symptom at both time periods. Average hours of sleep increased slightly between 5 and 11 weeks postpartum (from 6.4 to 6.8 hours per night), and the average number of awakenings declined slightly (from 2.6 to 2.0 awakenings per night). The net result was that fewer women reported "never or rarely" feeling refreshed after wakening in the morning with time $(30 \%$ at 11 weeks and $50 \%$ at 5 weeks postpartum).

The largest change in childbirth-related symptoms with time was associated with breastfeeding. For example, breast discomfort and nipple irritation decreased 
Table 1. Differences Between Women by 11-Week Interview Status ${ }^{\text {* }}$

\begin{tabular}{|c|c|c|c|c|}
\hline Variables & $\begin{array}{l}\text { Full Interview } \\
\qquad n=661 \\
\text { Mean (SD) }\end{array}$ & $\begin{array}{c}\text { Mini-Interview } \\
n=70 \\
\text { Mean (SD) }\end{array}$ & $\begin{array}{c}\text { Incomplete or } \\
\text { No Interview } \\
n=86 \\
\text { Mean (SD) }\end{array}$ & $\begin{array}{l}\text { Significance } \\
\text { of } F \text { Test Using } \\
\text { ANOVA or } t \text { Test }{ }^{\dagger} \\
\text { (P Value) }\end{array}$ \\
\hline \multicolumn{5}{|l|}{ Continuous } \\
\hline Age, years & $30(5.3)$ & $28.4(5.6)$ & $27.9(5.8)$ & $\mathrm{F}=7.86(.000)$ \\
\hline Preconception general health score & $3.1(0.8)$ & $3.0(0.7)$ & $3.0(0.9)$ & NS \\
\hline \multicolumn{5}{|l|}{ Postpartum health at 11 weeks } \\
\hline Mental health (MCS) score & $50.4(7.3)$ & $50.3(8.3)$ & - & NS \\
\hline Physical health (PCS) score & $55.7(5.2)$ & $54.5(8.7)$ & - & NS \\
\hline Discrete & Frequency (\%) & Frequency (\%) & Frequency (\%) & \\
\hline White & $568(86)$ & $49(70)$ & $64(74)$ & $\chi^{2}=17.1 ;$ df $2(.000)$ \\
\hline Earned a college degree & $318(48)$ & $18(26)$ & $18(21)$ & $x^{2}=32.6 ;$ df $2(.000)$ \\
\hline Meets poverty threshold & $81(12)$ & $10(14)$ & $17(20)$ & NS \\
\hline Prenatal mood problems & $307(46)$ & $36(51)$ & $42(49)$ & NS \\
\hline Primiparous & $301(46)$ & $31(44)$ & $38(44)$ & NS \\
\hline \multicolumn{5}{|l|}{ Employment (11 weeks) } \\
\hline Unemployed & 0 & $40(57)$ & - & $N S^{2 \ddagger}$ \\
\hline On leave & $334(51)$ & $11(16)$ & - & \\
\hline Working & $327(49)$ & $19(27)$ & - & \\
\hline
\end{tabular}

MCS = mental component summary from the SF-12; PCS = physicial component summary from the SF-12.

Note: Variables not significantly different between all 3 groups included the proportion of women by marital status, primiparous, and those who had cesarean deliveries; these findings are not reported in the table for purposes of brevity.

* The dashes indicate that no data was available for the subjects at the relevant time period because they did not do an interview at 5 and or 11 weeks after childbirth. t The $t$ test was used to evaluate differences in mean MCS and PCS scores between women completing the full interview and those completing the mini interview. ‡ The $\chi^{2}$ test was used to evaluate the difference in status as at work or on leave among employed women by interview status as full vs mini-interview. Women completing the mini-interview because they were unemployed were excluded from the analysis.

between 5 and 11 weeks postpartum (from $60 \%$ to $19 \%$, and $50 \%$ to $14 \%$, respectively). This pattern was consistent with a decline in breastfeeding from $67 \%$ to $52 \%$ between 5 and 11 weeks postpartum. Breastfeeding was less prevalent among mothers who had returned to work, compared with those on leave $(40.1 \%$ vs $\left.64.4 \%, \chi^{2}=39.1, \mathrm{df}=1, P=.000\right)$. The main exception to a pattern of declining symptoms with time was seen with mothers' respiratory symptoms. For example, symptoms of runny or stuffy nose, sore throat, cough and cold increased from 5 to 11 weeks postpartum (from $26 \%$ to $36 \%$ and $23 \%$ to $29 \%$, respectively).

\section{Multivariate Results}

\section{Women's Physical Health}

Factors significantly associated with better postpartum physical health included better preconception general health and higher levels of coworker support during pregnancy (Table 4). For example, when the PCS score is regressed on coworker support and other independent variables, the regression coefficient for coworker support is 3.17. The PCS score increased approximately 3 points as women's evaluation of their coworkers' support during pregnancy changed from a score of 0 (disagree) to 1 (agree).
Women's Mental Health

Factors significantly associated with better postpartum mental health included better preconception general health, an absence of prenatal mood problems, increased availability of social support from family and friends, more perceived control over home and work activities, and lower job stress scores (Table 4).

\section{Women's Postpartum Symptoms}

Factors significantly associated with fewer postpartum symptoms included better general preconception health, an absence of prenatal mood problems, being married or partnered (vs single), being nonwhite, and having an infant without colic (Table 4).

Findings from the multivariate analyses revealed that the effects of the independent variables on the measures of health were generally small to moderate in size. Ware and colleagues reported effects in these SF12 measures can be interpreted as very large (10 points or more), moderate to large (5 to 10 points), or small to moderate ( 2 to 5 points). ${ }^{23}$

\section{DISCUSSION}

These mothers continued to experience childbirthrelated symptoms at 11 weeks postpartum, with fatigue 
being the most frequent. Although most mothers have declining levels of fatigue over the first 2 weeks postpartum, some experience relentless fatigue. ${ }^{27}$ For these women, an intervention aimed at encouraging rest and quiet time may be essential for preventing depression. ${ }^{27}$ Postpartum fatigue may be caused by recovery from childbirth, childcare responsibilities, reduced sleep, and anemia. ${ }^{27-31}$ Infant sleep patterns and maternal fatigue have been shown to be strongly associated with the onset of depressive symptoms, ${ }^{27-30}$ suggesting that postpartum fatigue is important in its own right, and it may lead to other more serious problems.

Health concerns at 11 weeks postpartum were similar to those reported in our earlier study at 5 weeks postpartum, ${ }^{8}$ although the frequency of symptoms

\begin{tabular}{|c|c|}
\hline Variables & $\begin{array}{c}\text { Value } \\
\text { Mean (SD) }\end{array}$ \\
\hline \multicolumn{2}{|l|}{ Continuous } \\
\hline Maternal age (years) ${ }^{1^{*}}$ & $29.99(5.3)$ \\
\hline Preconception health ${ }^{*}$ & $3.10(0.8)$ \\
\hline \multicolumn{2}{|l|}{ ( 1 = poor/fair to $4=$ excellent) } \\
\hline Health services used, $\$^{\dagger}$ & $293(648)$ \\
\hline $\begin{array}{l}\text { Available social support } \\
\text { (summary score: } 5=\text { none of the time } \\
\text { to } 25=\text { all of the time) }\end{array}$ & $20.89(3.8)$ \\
\hline $\begin{array}{l}\text { Perceived control over home and } \text { work }^{* \neq} \\
(1=\text { no/little control to } 4=\text { complete } \\
\text { control) }\end{array}$ & $2.58(0.9)$ \\
\hline $\begin{array}{l}\text { Job satisfaction }(1=\text { very dissatisfied } \\
\text { to } 4=\text { very satisfied })^{\ddagger}\end{array}$ & $3.31(0.8)$ \\
\hline Discrete & Frequency (\%) \\
\hline Married or partnered ${ }^{\dagger}$ & $585(88.5)$ \\
\hline College educated $^{*}$ & $318(48.1)$ \\
\hline White ${ }^{*}$ & $568(85.9)$ \\
\hline Meets state threshold for poverty status* & $81(12.3)$ \\
\hline Prenatal mood problems ${ }^{2 *}$ & $307(46.4)$ \\
\hline Primiparous* & $301(45.5)$ \\
\hline Any breastfeeding ${ }^{\dagger}$ & $346(52.3)$ \\
\hline Infant girl $3^{3^{*}}$ & $332(50.2)$ \\
\hline $\begin{array}{l}\text { Employment status (back to work at } \\
11 \text { weeks postpartum) }{ }^{\dagger}\end{array}$ & $327(49.5)$ \\
\hline \multicolumn{2}{|l|}{ Occupational classification ${ }^{\dagger}$} \\
\hline Blue collar/service & $94(14.2)$ \\
\hline Clerical & $248(37.5)$ \\
\hline Professional & $319(48.3)$ \\
\hline Job always or usually stressful ${ }^{\ddagger}$ & $172(26 \%)$ \\
\hline High job-related psychological demands' & $347(52.5)$ \\
\hline High job-related decision latitude ${ }^{\dagger}$ & $348(52.6)$ \\
\hline Supportive supervisor ${ }^{\ddagger}$ & $601(90.9)$ \\
\hline Supportive coworkers ${ }^{\ddagger}$ & $652(98.6)$ \\
\hline Colicky babył & $45(6.8)$ \\
\hline
\end{tabular}

generally decreased with time. The main exception to this pattern was an increase in respiratory symptoms with time consistent with earlier findings by Gjerdingen et al. ${ }^{4}$ These authors reported that respiratory symptoms increased from childbirth to 3 months postpartum and remain elevated for the remainder of the first postpartum year. They hypothesized that the postpartum increase in respiratory symptoms may have resulted from mothers' exposures to infection in the workplace, infants' exposures at day care, or increased susceptibility to infection due to work stress. ${ }^{4}$ The relationship between psychological stress and increased risk for developing respiratory illness has been reported in laboratory studies by Cohen, and the longer the duration of the stressor, the greater the risk. ${ }^{32}$

The largest decline in childbirth-related symptoms was in breast symptoms. There are many likely factors contributing to this trend. For example, the approximately threefold decrease in the prevalence of breast discomfort and nipple irritation between 5 and 11 weeks postpartum may reflect mothers' adaptation to breastfeeding, as such symptoms are more common in the early stages of lactation. Additionally, the decline in symptoms may partially reflect the decreased prevalence in breastfeeding from $67 \%$ at 5 weeks to $52 \%$ at 11 weeks postpartum. This decline in breastfeeding with time and in association with full-time work among study participants is consistent with national estimates. ${ }^{41-42}$

State law requires employers to provide daily unpaid break time for a mother to express breast milk for her infant. Employers are also required to make a reasonable effort to provide a private location for this activity. ${ }^{43}$ The extent to which employers provide these benefits or to which women find these benefits sufficient incentives to continue breastfeeding upon return to work is unclear. Research addressing these issues is needed.

Factors associated with better health at both 5 and 11 weeks postpartum included better preconception health, no prenatal mood problems, greater perceived control, more social support, and no infant colic. Factors significantly associated with better health at 5 weeks (but not at 11 weeks) postpartum included vaginal delivery (vs cesarean section) and not breastfeeding. Factors significantly associated with better health at 11 weeks (but not 5 weeks) postpartum included less job stress, more coworker support, being married or partnered, and nonwhite race.

Better preconception health was associated with better postpartum health at 11 weeks after childbirth across all measures. This result is consistent with national recommendations to promote women's health before conception to improve childbirth-related outcomes. ${ }^{33}$ One-third to one-half of women have more 
than 1 primary care clinician, ${ }^{33}$ thus all clinicians who treat women play an important role in improving preconception health and health care. Women who exhibit lower levels of mental or physical health before pregnancy should be more closely monitored during the postpartum period. Their clinicians may want to consider more frequent health care visits.

Prenatal mood problems were an important correlate of poorer postpartum mental health and higher symptom levels, a finding consistent with other studies. ${ }^{34,35}$ Physicians may want to explore the use of established screening tools to assist with evaluating women's mental health during prenatal visits and should be prepared to treat or facilitate treatment of mental disorders.

Social support from family and friends was significantly related to better postpartum mental health, as reported in other studies. ${ }^{11,12}$ Additionally, women who were married or living with partners had better postpartum health, a finding consistent with reports in the medical literature addressing the positive association of marriage and health at later life stages. ${ }^{36-38}$ Research is needed to assess whether educational interventions would be helpful (eg, discussions on the nature of support, its importance to well-being, and how to access support in times of need).

The finding of a small, but statistically significant association between nonwhite race and fewer symptoms was unexpected. The relevance of the finding is limited given the diversity of mothers categorized as nonwhite (eg, $7.3 \%$ black, $4.2 \%$ Asian Pacific Islander, and 2.6\% other). This finding may also be due to cultural differences in reporting symptoms

Mothers' better postpartum health status was also associated with several work-related variables, including lower levels of job stress, increased perceived control over work (and home) activities, and more coworker support. The relationship between mothers' mental health and lower levels of job stress suggests a need for research on factors associated with job stress (eg, duration of work hours and flexible work arrangements).

Greater levels of perceived control over work and home activities were associated with significantly better mental health, which is consistent with findings from studies investigating control over work and mental health. ${ }^{39,40}$ Research is needed to identify factors that may enhance women's sense of control at work and home (eg, paid leave benefits and high-quality substitute child care).

In this study, women who believed their coworkers were helpful to them during pregnancy had significantly better postpartum 
MOTHERS AT 11 WEEKS POSTPARTUM

\begin{tabular}{|c|c|c|c|c|c|c|}
\hline \multirow[b]{2}{*}{ Independent Variables } & \multicolumn{2}{|c|}{ Physical Health* } & \multicolumn{2}{|c|}{ Mental Health ${ }^{\dagger}$} & \multicolumn{2}{|c|}{ Symptoms } \\
\hline & Coefficients (SE) & $P$ Value & Coefficients (SE) & $P$ Value & Coefficients (SE) & $P$ Value \\
\hline Preconception health & $3.42(0.53)$ & $.0001^{\ddagger}$ & $1.61(0.70)$ & $.022^{\ddagger}$ & $-1.28(0.43)$ & $.003^{\ddagger}$ \\
\hline Married/partnered & $-0.58(0.83)$ & .487 & 1.59 (1.09) & .145 & $-1.75(0.67)$ & $.009 \ddagger$ \\
\hline Race (white) & $0.28(0.69)$ & .700 & $-1.57(0.91)$ & .086 & $1.18(0.56)$ & $.034^{\ddagger}$ \\
\hline Infant colic & $-1.25(1.06)$ & .240 & $-2.26(1.39)$ & .104 & $2.52(0.85)$ & $.003^{\ddagger}$ \\
\hline Job stress & $0.39(0.54)$ & .473 & $-2.08(0.71)$ & $.004^{\ddagger}$ & $0.71(0.44)$ & .110 \\
\hline Coworker support & $3.17(1.30)$ & $.015^{\ddagger}$ & $0.64(1.70)$ & .707 & $-0.62(1.04)$ & .550 \\
\hline Prenatal mood problems & $0.36(0.65)$ & .582 & $-2.93(0.85)$ & $.001^{\ddagger}$ & $1.00(0.52)$ & .057 \\
\hline Perceived control & $0.39(0.297)$ & .957 & $1.16(0.39)$ & $.003^{\ddagger}$ & $-0.12(0.24)$ & .620 \\
\hline Social support & $-0.01(0.093)$ & .902 & $0.52(0.12)$ & $.000^{\ddagger}$ & $-0.14(0.07)$ & .072 \\
\hline \multicolumn{7}{|l|}{$2 S L S=2$-stage least squares } \\
\hline \multicolumn{7}{|c|}{ Note: Regression coefficients not statistically significant in any of the 3 equations are not reported. } \\
\hline \multicolumn{7}{|c|}{$\begin{array}{l}\text { * Measured with the PCS (physical component summary of the SF-12) score. } \\
\text { † Measured with the MCS (mental component summary of the SF-12) score. } \\
\text { \& Statistically significant t test on the estimated 2SLS regression coefficient. }\end{array}$} \\
\hline
\end{tabular}

physical health, and is consistent with the findings of Killien et al. ${ }^{13}$ Future research should examine the mechanisms through which coworkers' support may influence health.

Mother's leave status was not significantly associated with postpartum health at 11 weeks after childbirth. Although this finding may seem contrary to earlier research documenting a positive association between a longer duration of leave and health outcomes, ${ }^{5,34}$ the earlier studies, which also used measures of selfreported health status, found that the positive effect of leave on health required a longer duration of time to show an effect. Thus a positive association of leave on vitality was documented after 12 weeks of leave, ${ }^{5}$ and on mental health at 15 weeks in one study ${ }^{5}$ and on mental health at 24 weeks or more in a second study. ${ }^{34}$ The current cohort of study participants will be followed for 18 months after childbirth. This longitudinal follow-up will enable us to evaluate the effect of leave on health over time and will be the focus of future papers.

In the first few months after childbirth, some new mothers may adapt better upon return to work with an intermittent rather than straight-time family and medical leave. Intermittent leave under FMLA allows return to work on a gradual, part-time basis over a longer duration than 12 weeks. ${ }^{*}$ Women with fatigue or postpartum symptoms that limit daily activities may find intermittent leave helpful, although research is needed to evaluate this proposition. When required by the employer, physicians, however, must certify

For example, if a woman works full-time before her leave and takes the maximum 12 weeks of FMLA leave straight-time, when she returns to work she goes from full-time leave to full-time work. In contrast, she might take 8 weeks of FMLA leave straight-time, and take her remaining 4 weeks as intermittent leave, working $50 \%$ effort for 8 weeks before returning to work at $100 \%$ effort. intermittent leave as necessary for the mother's "serious health condition" in relation to childbirth, as defined in the FMLA regulation. ${ }^{44}$

Not all women are eligible for FMLA-related leave from work, as they may not meet the employment requirements or their employer may be too small to fall within FMLA guidelines. Even so, many states mandate some benefits for childbirth-related leave. For example, Minnesota's parental leave law applies to employers with 21 or more employees, ${ }^{45}$ thus it extends job-protected leave to new mothers working at smaller firms with 21 to 49 employees that are otherwise not covered by the FMLA. Additionally, firms may offer paid vacation or sick leave benefits. Physicians will want to discuss with new mothers their available benefits and explore what medical certification would be helpful to assist them in their postpartum recovery and return to work.

\section{Limitations}

While study findings are internally valid, they can be generalized only to women of comparable demographic and income levels. Additional studies on employed women from other racial, ethnic, and economic backgrounds are needed. This study used a prospective cohort design and observed women for 18 months postpartum. This study design enables women to serve as their own baseline, as late health outcomes (18 months postpartum) will be compared with early health outcomes (5 or 11 weeks postpartum). Future studies, however, would benefit from a case control design enabling comparison of employed postpartum women with similar women who are not postpartum to inform the literature on the prevalence of symptoms in both populations. 
This study focused only on mothers' postpartum health. Fathers may also experience changes in their physical and mental health in association with the birth of a baby and related life style changes. Additionally, this study did not incorporate specific measures of a spouse or partner's helpfulness around the house or use of family leave to assist with the infant care. Although this study did include a multidimensional measure of available social support from family and friends, future studies designed to assess both mothers' and fathers' health and fathers' contribution to infant care would help inform family physicians on the care of new parents. Finally, because we examined several variables in a single regression, the probability was greater than 0.05 under the null hypotheses that at least 1 variable would be found to be significant at $P<.05$ due to the phenomenon of multiple inference. Because we focused on the effects of each individual variable, however, we chose not to control for experiment-wide type 1 error and so did not adjust the $P$ values.

At 11 weeks postpartum these employed mothers continued to experience several childbirth-related symptoms, indicating a need for ongoing rest and recovery. Physicians evaluating postpartum women may want to discuss strategies to promote health, including identification of sources of social support at home and work. Postpartum evaluations should include screening for anxiety and depression and evaluation of fatigue and other physical symptoms, including those related to job stress. Physicians should discuss with women their plans for return to work and possible need for intermittent leave under FMLA. Studies evaluating interventions using these suggested practices are needed.

To read or post commentaries in response to this article, see it online at http://www.annfammed.org/cgi/current/full/5/6/519.

Submitted November 6, 2006; submitted revised March 10, 2007; accepted May 18, 2007.

Key words: Postpartum period; postnatal care; maternal welfare; women's health

Variations of this work were reported as follows: "After Birth: Women, Work and Health," P. McGovern, with D. Gjerdingen, B. Dowd, R. Dagher, L. Ukestad, D. McCaffrey, Division of Epidemiology Seminar, School of Public Health, University of Minnesota, October 27, 2006; "Twelve Weeks After Birth: Women, Work \& Health," P. McGovern with B. Dowd, D. Gjerdingen, R. Dagher, L. Ukestad, D. McCaffrey, Ulf Lundberg, AcademyHealth Annual Research Meeting, Seattle, Washington, June 25, 2006; "After Birth: Policies that Promote Healthy Women and Workplaces," P. McGovern with B. Dowd, D. Gjerdingen, S. Kenney, L. Ukestad, D. McCaffrey, Ulf Lundberg, Work, Stress \& Health, cosponsored by the National Institute for Occupational Safety and Health (NIOSH) \& the American Public Health Association (APA), Miami, Florida, March 2, 2006; "Work Organization \& Postpartum Health in Employed Mothers after Childbirth," oral and poster presentation by P. McGovern with D. Gjerdingen, B. Dowd, R. Dagher, L. Ukestad,
D. McCaffrey, U. Lundberg, National Occupational Research Agenda (NORA) Symposium 2006, Washington DC, April 19, 2006; "Work Organization \& Postpartum Health In Employed Mothers After Childbirth," poster presentation by P. McGovern with D. Gjerdingen, B. Dowd, R. Dagher, L. Ukestad, D. McCaffrey, U. Lundberg, The Midwest Center for Occupational Safety \& Health Advisory Board Meeting, NORA Poster Exhibit, Minneapolis, Minnesota, April 13, 2006.

Funding support: This publication was supported by grant 5 R18 OH003605-05 from the National Institute for Occupational Safety and Health (NIOSH).

Disclaimer: The contents of this report are solely the responsibility of the authors and do not necessarily represent the official views of NIOSH.

\section{References}

1. US Census Bureau. Women 15 to 44 years old who had a child in the last year and their percentage in the labor force: selected years, 1976 to 2004. Washington, DC: US Census Bureau, Fertility and Family Statistics Branch, 1990-2004. http://www.census.gov/ population/socdemo/fertility/tabH5.xls. Accessed May 31, 2006.

2. US Department of Labor. Employment characteristics of families summary. News, Bureau of Labor Statistics. Washington, DC: US Department of Labor; 2006. http://www.bls.gov/news.release/ famee.nrO.htm. Accessed April 27, 2006.

3. Overturf Johnson J, Downs B. Maternity leave and employment patterns: 1961-2000. Current population report, P70-103. Washington, DC: US Census Bureau; 2003:14.

4. Gjerdingen DK, Froberg DG, Chaloner KM, McGovern PM. Changes in women's physical health during the first postpartum year. Arch Fam Med. 1993;2(3):277-283.

5. McGovern P, Dowd B, Gjerdingen D, Moscovice I, Kochevar L, Lohman W. Time off work and the postpartum health of employed women. Med Care. 1997;35(5):507-521.

6. Brown S, Lumley J. Maternal health after childbirth. Br J Obstet Gynaecol. 1998;105(2):156-161.

7. Killien MG, Habermann B, Jarrett M. Influence of employment characteristics on postpartum mothers' health. Women Health. 2001;33(1-2):63-81.

8. McGovern P, Dowd B, Gjerdingen D, et al. Postpartum health of employed mothers 5 weeks after childbirth. Ann Fam Med. 2006;4(2):159-167.

9. Fisher JRW, Feekery CJ, Rowe-Murphy HJ. Nature, severity and correlates of psychological distress in women admitted to a private mother-baby unit. J Paediatr Child Health. 2002;38(2):140-145.

10. Gjerdingen DK, Center BA. First-time parents' prenatal to postpartum changes in health, and the relation of postpartum health to work and partner characteristics. J Am Board Fam Pract. 2003;16(4):304-311.

11. Dennis CL. Influence of depressive symptomatology on maternal health service utilization and general health. Arch Womens Ment Health. 2004;7(3):183-191.

12. Seimyr L, Edhborg M, Lundh W, Sjögren B. In the shadow of maternal depressed mood: experiences of parenthood during the first year after childbirth. J Psychosom Obstet Gynaecol. 2004;25(1):23-34.

13. Killien MG. The role of social support in facilitating postpartum women's return to employment. J Obstet Gynecol Neonatal Nurs. 2005;34(5):639-646.

14. U.S. Department of Health and Human Services. Healthy People 2010: Volume II 2nd ed. 2000. http://www.healthypeople.gov/document/ html/objectives/16-19.htm.\#volume2. Accessed September 14, 2005. 
15. Li R, Darling N, Maurice E, Barker L, Grummer-Straawn LM. Breastfeeding rates in the United States by characterization of the child, mother or family: the 2002 National Immunization Survey. Pediatrics. 2005;115(1):e31-e37.

16. National Conference of State Legislatures. 50 State Summary of Breastfeeding Laws, 2006. Denver. http://www.ncsl.org/programs/ health/breast50.htm. Accessed May 2, 2006.

17. Haas JS, Jackson RA, Fuentes-Afflick $E$, et al. Changes in the health status of women during and after pregnancy. J Gen Intern Med. 2005;20(1):45-51.

18. Casta N. Highlights of the 2000 U.S. Department of Labor Report. Balancing the Needs of Families and Employers: Family and Medical leave Surveys. Washington, DC: National Partnership for Women \& Families.

19. 29 USC $§ 2611(2)$

20. National Partnership for Women \& Families. State by State Guide to Unpaid, Job-Protected Family and Medical Leave Laws, 2003. http:// www.nationalpartnership.org/site/. Accessed January 22, 2007.

21. Becker G. A Theory of the allocation of time. Econ J. 1965;75(299):493-517.

22. Grossman M. The Demand for Health: a Theoretical and Empirical Investigation. Occasional Paper 119, National Bureau of Economic Research, New York, NY: Columbia University Press;1972:1-83.

23. Ware J, Kosinski M, Turner-Bowker D, Gandek B. Version 2 of the SF12 Health Survey. Lincoln: QualityMetric Inc; 2002:3-7, 89,159.

24. Kennedy P. A Guide to Econometrics. 5th ed. Cambridge, MA: MIT Press, 2003:188-189.

25. Bachu A, O'Connell M. Fertility of American Women. Washington, DC: US Census Bureau; 2001.

26. National Center for Health Statistics. Births, Percentages of births by race, 2000-2002. PeriStats, 2005. http://www.marchofdimes. com/peristats. Accessed September 20, 2005.

27. Corwin EJ, Brownstead J, Barton N, Heckard S, Morin K. the Impact of fatigue on the development of postpartum depression. J Obstet Gynecol Neonatal Nurs. 2005;34(5):577-586.

28. Dennis CL, Ross L. Relationships among infant sleep patterns, maternal fatigue and development of depressive symptomatology. Birth. 2005;32(3):187-193.

29. Groer M, Davis M, Casey K, Short B, Smith K, Groer S. Neuroendocrine and immune relationship in postpartum fatigue. MCN Am J Matern Child Nurs. 2005;30(2):133-138.
30. Bozoky I, Corwin EJ. Fatigue as a predictor of postpartum depression. J Obstet Gynecol Neonatal Nurs. 2002(4):436-443.

31. Lee K, Zaffke M. Longitudinal changes in fatigue and energy during pregnancy and the postpartum period. J Obstet Gynecol Neonatal Nurs. 1999;28(2):183-191.

32. Cohen S. The Pittsburgh common cold studies: Psychosocial predictors of susceptibility to respiratory infections illness. Int J Behav Med. 2005;12(3):123-131.

33. MMWR. Recommendations to improve preconception health and health care. A Report of the CDC/ATSDR Preconception Care Work Group and the Select Panel on Preconception Care United States. MMWR Recomm Rep. 2006;55(RR-6):1-23.

34. Gjerdingen DK, Chaloner KM. The relationship of women's postpartum mental health to employment, childbirth, and social support. J Fam Pract. 1994;38(5):465-472.

35. Beck CT. Predictors of postpartum depression. Nurs Res. 2001;50(5):275-285.

36. Kahn RS, Wise PH, Kennedy BP, Kawachi I. State income inequality, household income and maternal mental and physical health. BMJ. 2000;321(7272):1311-1315.

37. Waldron I, Weiss C, Hughes M. Interacting effects of multiple roles on women's health. J Health Soc Behav. 1998;39(3):216-236.

38. Waldron I, Weiss C, Hughes M. Marital status effects on health are there differences between never married women and divorced and separated women? Soc Sci Med. 1997;45(9):1387-1397.

39. Wang J, Patten SB. Perceived work stress and major depression in the Canadian employed population, 20-49 years old. J Occup Health Psychol. 2001;6(4):283-289.

40. Mazure C, Keita G, Blehar M. Summit on Women and Depression: Proceedings and Recommendations. Washington, DC, American Psychological Association; 2002:31.

41. Fein SB, Roe B. The effect of work status on initiation and duration of breastfeeding. Am J Public Health. 1998;88(7):1042-1046.

42. Deshpande A, Gazmarapian J. Breast-feeding education and support. American College of Physicians. 2000. http://www.acponline.org/ journals/ecp/mayjun00/deshpande.htm. Accessed September 14, 2005.

43. Minn Stat $§ 181.939$

44. 29 USC §2611(11): 29 C.F.R. §825.305(a); 29 C.F.R. §825.306(b)(2)(ii)

45. Minn Stat $§ 181.941$ 